\title{
Numerical Solution of MHD Convection and Mass Transfer Flow of Viscous Incompressible Fluid about an Inclined Plate with Hall Current and Constant Heat Flux
}

\author{
Mohammad Wahiduzzaman', Runu Biswas², Md. Eaqub Ali³, Md. Shakhaoath Khan", \\ Ifsana Karim ${ }^{4}$ \\ ${ }^{1}$ Mathematics Discipline, Khulna University, Khulna, Bangladesh \\ ${ }^{2}$ Mathematics Open School, Bangladesh Open University, Gazipur, Bangladesh \\ ${ }^{3}$ Department of Civil Engineering, Sonargaon University, Dhaka, Bangladesh \\ ${ }^{4}$ Discipline of Chemical Engineering, The University of Newcastle, Callaghan, Australia \\ Email:wahidmathku@gmail.com,runu_biswas@yahoo.com, eaqubali94@yahoo.com, \\ mdshakhaoath.khan@uon.edu.au,ifsana.karim@uon.edu.au
}

Received 14 November 2015; accepted 27 December 2015; published 30 December 2015

Copyright (C) 2015 by authors and Scientific Research Publishing Inc.

This work is licensed under the Creative Commons Attribution International License (CC BY).

http://creativecommons.org/licenses/by/4.0/

(c) (i) Open Access

\begin{abstract}
The present numerically study investigates the influence of the Hall current and constant heat flux on the Magneto hydrodynamic (MHD) natural convection boundary layer viscous incompressible fluid flow in the manifestation of transverse magnetic field near an inclined vertical permeable flat plate. It is assumed that the induced magnetic field is negligible compared with the imposed magnetic field. The governing boundary layer equations have been transferred into non-similar model by implementing similarity approaches. The physical dimensionless parameter has been set up into the model as Prandtl number, Eckert number, Magnetic parameter, Schmidt number, local Grashof number and local modified Grashof number. The numerical method of NactsheimSwigert shooting iteration technique together with Runge-Kutta six order iteration scheme has been used to solve the system of governing non-similar equations. The physical effects of the various parameters on dimensionless primary velocity profile, secondary velocity profile, and temperature and concentration profile are discussed graphically. Moreover, the local skin friction coefficient, the local Nusselt number and Sherwood number are shown in tabular form for various values of the parameters.
\end{abstract}

\section{Keywords}

MHD, Heat and Mass Transfer, Hall Current, Inclined Plate, Constant Heat Flux

How to cite this paper: Wahiduzzaman, M., Biswas, R., Ali, Md.E., Khan, Md.S. and Karim, I. (2015) Numerical Solution of MHD Convection and Mass Transfer Flow of Viscous Incompressible Fluid about an Inclined Plate with Hall Current and Constant Heat Flux. Journal of Applied Mathematics and Physics, 3, 1688-1709. 


\section{Introduction}

Hall current has important contribution in the study of MHD viscous flows. It has many applications in problems of the Hall accelerators as well as in the flight MHD. The current trend is on the application of MHD towards a strong magnetic field and a low density of gas. For this reason, the Hall current and ion slip become important. Hydrodynamic flow of a viscous liquid through a straight channel in presence of Hall Effect is examined by Sato [1], Yamanishi [2], and Sherman and Sutton [3]. The Hall current effects on the boundary layer flow past a semi-infinite plate are studied by Katagiri [4]. Free convection flow of a conducting fluid permeated by a transverse magnetic field in the presence of the Hall effects and uniform magnetic field is analyzed by Pop and Watanabe [5]. Aboeldahab and Elbarbary [6] studied the effect of the Hall current on the MHD free convection flow in the presence of foreign species over a vertical surface, where the flow is subjected to a strong external magnetic field. Eichhorn [7] investigated the similarity solution by considering the power-law variations in the plate temperature and transpiration velocity. Vedhanayagam et al. [8] worked on the free convection flow along a vertical plate with the arbitrary blowing and wall temperature. Lin and $\mathrm{Yu}$ [9] investigated the free convection flow over a horizontal plate. Recently, Hossain et al. [10] investigated the natural convection flow from a vertical permeable flat plate with the variable surface temperature, considering the temperature and transpiration rates to follow the power-law variation. Saha et al. [11] studied the effect of Hall current on the steady laminar natural convection boundary layer flow of MHD viscous and incompressible fluids. Lately, Saha et al. [12] examined the effect of Hall current on MHD natural convection flow from vertical permeable flat plate with uniform surface heat flux. In recent years a number of studies of MHD convective heat and mass transfer boundary layer flow of viscous incompressible fluid were reported in the literature [13]-[25]. However, the effect of hall current and constant heat flux is still not getting promising attraction to the researchers. In this study MHD Free Convection and Mass Transfer Flow of Viscous Incompressible Fluid about an inclined Plate with Hall Current and Constant Heat Flux is investigated.

\section{Mathematical Analysis}

Steady natural convection boundary layer flow of an electrically conducting and viscous incompressible fluid from a semi-infinite heated permeable inclined flat plate with a uniform surface heat flux and transverse magnetic field with the effect of the Hall current is considered. Here $x$ axis is taken along the vertically upward direction and $y$ axis is normal to it. The leading edge of the permeable surface is taken along $z$ axis. The uniform heat is supplied from the surface of the plate to the fluid, which is maintained uniformly throughout the fluid flow. The temperature and concentration at the wall are $T_{w}$ and $C_{w}$ respectively. The temperature and concentration outside the boundary layer are $T_{\infty}$ and $C_{\infty}$ respectively. Uniform magnetic field of magnitude $B_{0}$ is imposed to perpendicular to the flow along the $y$ axis. Let the angle of inclination of the plate is $\gamma$ and the plate is semi finite. The $x$ component momentum equation reduces to the boundary layer equation if and only if body force is made by gravity, then the body force per unit mass is $F_{x}=-\rho g_{0} \cos \gamma$, where $g_{0}$ is the acceleration due to gravity. Further no body force exists in the direction of $y$ and z, i.e. $\frac{\partial p}{\partial y}=0, \frac{\partial p}{\partial z}=0$, and $F_{y}=0$, $F_{z}=0$. The $x$ component of pressure gradient at any point in the boundary layer must equal to the pressure gradient in the region outside the boundary layer, in this region $u=0, v=0$. Hence $x$ component of pressure gradient become $\frac{\partial p}{\partial x}=-\rho_{\infty} g_{0} \cos \gamma$, where $\rho_{\infty}$ is the density of the surrounding fluid at temperature $T_{\infty}$. The quantity $\rho-\rho_{\infty}$ is related to the temperature difference $T-T_{\infty}$ and concentration (or mass) differences $C-C_{\infty}$ through the thermal volume expansion coefficient $\beta$ and concentration volume expansion coefficient $\beta^{*}$ by the relation, $\frac{\rho-\rho_{\infty}}{\rho}=-\beta\left(T-T_{\infty}\right)-\beta^{*}\left(C-C_{\infty}\right)$, therefore,

$$
F_{x}-\frac{1}{\rho} \frac{\partial p}{\partial x}=g_{0} \beta\left(T-T_{\infty}\right) \cos \gamma+g \beta^{*}\left(C-C_{\infty}\right) \cos \gamma .
$$

We have the generalized ohm's law in the absence of electric field to the case of short circuit problem is of the form 


$$
\underline{J}+\frac{\omega_{e} \tau_{e}}{B_{0}} \underline{J} \times \underline{B}=\sigma\left(\underline{E}+\mu_{e} \underline{q} \times \underline{B}\right)
$$

where, $\mu_{e}$ is the magnetic permeability, $\tau_{e}$ is the electron collision time, $\sigma$ is the electrical conductivity, $\omega_{e}$ is the cyclotron frequency, $B_{0}$ is the applied magnetic field. Since no applied or polarized voltage exist, so the effect of polarization of fluid is negligible, i.e. $\underline{E} \equiv(0,0,0)$.

Therefore Equation (1) becomes

$$
\underline{J}+\frac{\omega_{e} \tau_{e}}{B_{0}} \underline{J} \times \underline{B}=\sigma \mu_{e}(\underline{q} \times \underline{B}) .
$$

If is assumed that induced magnetic field generated by fluid motion is negligible in comparison to the applied one i.e. $\underline{B} \equiv\left(0, B_{0}, 0\right)$. This assumption is valid because magnetic Reynolds number is very small for liquid metals and partially ionized fluids.

Since the Hall coefficient is $m=\omega_{e} \tau_{e}$, so the Equation (2) we can write

$$
\begin{aligned}
& J_{z}=\frac{\sigma \mu_{e} B_{0}}{1+m^{2}}(m w+u) \\
& J_{x}=\frac{\sigma \mu_{e} B_{0}}{1+m^{2}}(m u-w)
\end{aligned}
$$

where $J_{y}=0$. The fundamental equations for the steady incompressible MHD flow with the generalized Ohm's law and Maxwell's equations, under the assumptions that the fluid is quasi-neutral, and the ion slip and thermoelectric effects can be neglected. Since the plate is semi-infinite and motion is steady, all physical equations will be the functions of $x$ and $y$. Thus mathematically the problem reduces to a two dimensional problem given as follows:

$$
\begin{gathered}
\frac{\partial u}{\partial x}+\frac{\partial u}{\partial y}=0 \\
u \frac{\partial u}{\partial x}+v \frac{\partial u}{\partial y}=v \frac{\partial^{2} u}{\partial y^{2}}+g_{0} \beta\left(T-T_{\infty}\right) \cos \gamma+g \beta^{*}\left(C-C_{\infty}\right) \cos \gamma-\frac{\sigma B_{0}^{2}}{\rho\left(1+m^{2}\right)}(u+m w) \\
u \frac{\partial w}{\partial x}+v \frac{\partial w}{\partial y}=v \frac{\partial^{2} w}{\partial y^{2}}+\frac{\sigma B_{0}^{2}}{\rho\left(1+m^{2}\right)}(m u-w) \\
u \frac{\partial T}{\partial x}+v \frac{\partial T}{\partial y}=\frac{k}{\rho c_{p}} \frac{\partial^{2} T}{\partial y^{2}}+\frac{v}{c_{p}}\left[\left(\frac{\partial u}{\partial y}\right)^{2}+\left(\frac{\partial w}{\partial y}\right)^{2}\right] \\
u \frac{\partial C}{\partial x}+v \frac{\partial C}{\partial y}=D_{m} \frac{\partial C}{\partial y^{2}}
\end{gathered}
$$

Subjected to the boundary conditions

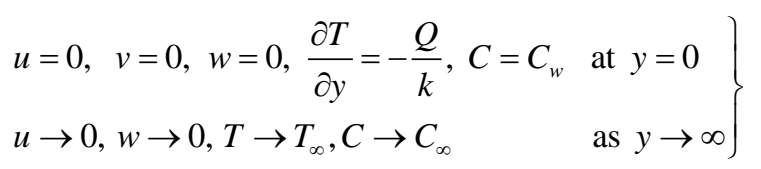

where $u, v, w$ are the velocity components in the $x, y, z$ direction respectively, $v$ is the kinematics viscosity, $\rho$ is the density. $T, T_{w}$ and $T_{\infty}$ are the temperature of the fluid inside the thermal boundary layer, the plate temperature and the fluid temperature in the free stream, respectively, while $C, C_{w}, C_{\infty}$ are the corresponding concentrations. Also, $\sigma$ is the electric conductivity of the medium, $k$ is the thermal conductivity of the medium, $D_{m}$ is the coefficient of mass diffusivity, $c_{p}$ is the specific heat at constant pressure, $Q$ is the constant heat flux per unit area and other symbols have their usual meaning.

In order to solve the above system (Figure 1) of Equations (6)-(9) with the boundary conditions (10), we 


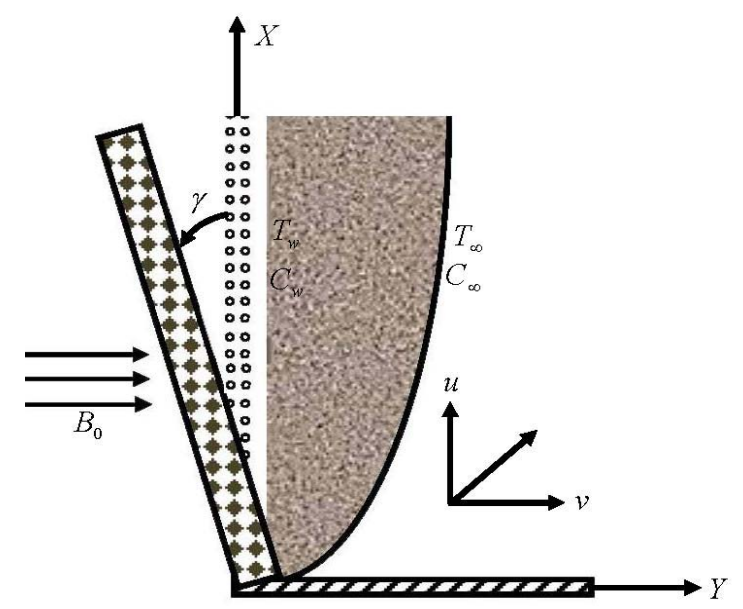

Figure 1. Physical configuration and co-ordinate system.

adopt the well-defined similarity analysis to attain similarity solutions. For this purpose, the following similarity transformations are now introduced;

$$
\begin{gathered}
\eta=y \sqrt{\frac{U_{0}}{2 v x}}, \quad g_{0}(\eta)=\frac{w}{U_{0}}, \theta(\eta)=\frac{k\left(T-T_{\infty}\right)}{Q} \sqrt{\frac{U_{0}}{2 v x}}, \\
\phi(\eta)=\frac{C-C_{\infty}}{\left(C_{0}-C_{\infty}\right)}, \psi=\sqrt{2 v x U_{0}} f(\eta) \therefore u=\frac{\partial \psi}{\partial y}=U_{0} f^{\prime}(\eta) \text { and } v=-\frac{\partial \psi}{\partial x}=\sqrt{\frac{U_{0} v}{2 x}}\left[\eta f^{\prime}(\eta)-f(\eta)\right] .
\end{gathered}
$$

Thus, Equations (6)-(10) becomes;

$$
\begin{gathered}
f^{\prime \prime \prime}+f f^{\prime \prime}+G_{r} \cos \gamma \theta+G_{m} \cos \gamma \varphi-\frac{M}{1+m^{2}}\left(f^{\prime}+m g\right)=0 \\
g^{\prime \prime}+f g^{\prime}+\frac{M}{1+m^{2}}\left(m f^{\prime}+g\right)=0 \\
\theta^{\prime \prime}+P_{r} E_{c}\left[\left(f^{\prime \prime}\right)^{2}+\left(g^{\prime}\right)^{2}\right]-P_{r}\left(f^{\prime} \theta-f \theta^{\prime}\right)=0 \\
\varphi^{\prime \prime}+S_{c} f \varphi^{\prime}=0 .
\end{gathered}
$$

The corresponding boundary conditions are

$$
\left.\begin{array}{l}
f^{\prime}(\eta)=0, g(\eta)=0, \theta^{\prime}(\eta)=-1 \\
\varphi(\eta)=1 \quad \text { at } \eta=0 \\
f^{\prime}(\eta) \rightarrow 0, g(\eta) \rightarrow 0, \theta(\eta) \rightarrow 0 \\
\varphi(\eta) \rightarrow 0 \quad \text { at } \eta \rightarrow \infty
\end{array}\right\}
$$

where $P_{r}=\frac{k}{\rho C_{p} v}$ is the Prandtl number, $E_{c}=\frac{U_{0}^{3} k}{C_{p} Q \sqrt{2 v x U_{0}}}$ is the Eckert number, $M=\frac{2 x \sigma B_{0}^{2}}{\rho U_{0}}$ is the Magnetic parameter, $S_{c}=\frac{v}{D_{m}}$ is the Schmidt number, $G_{r}=\frac{g_{0} \beta Q \sqrt{2 x}}{k U_{0} \sqrt{v U_{0}}}$ is the local Grashof number, $G_{m}=\frac{2 g \beta^{*}\left(C_{w}-C_{\infty}\right) x}{U_{0}^{2}}$ is the local modified Grashof number. Similarity transformations expressions also satisfy the continuity Equation (5). 


\section{Skin-Friction Coefficients, Nusselt Number and Sherwood Number}

The quantities of chief physical interest are the skin friction coefficients, the Nusselt number and the Sherwood number. The equation defining the wall skin frictions are $\tau_{x}=\mu\left(\frac{\partial u}{\partial y}\right)_{y=0}$ and $\tau_{z}=\mu\left(\frac{\partial w}{\partial y}\right)_{y=0}$ which are proportional to $\left(\frac{\partial^{2} f}{\partial \eta^{2}}\right)_{\eta=0}$ and $\left(\frac{\partial g}{\partial \eta}\right)_{\eta=0}$. The Nusselt number denoted by $N_{u}$ is proportional to $-\left(\frac{\partial T}{\partial y}\right)_{y=0}$, hence we have $N_{u} \infty-\theta^{\prime}(0)$. The Sherwood number denoted by $S_{h}$ is proportional to $-\left(\frac{\partial C}{\partial y}\right)_{y=0}$, hence we have $S_{h} \infty-\varphi^{\prime}(0)$. The numerical values of the skin-friction coefficients, the Nusselt number and the Sherwood number are sorted in Tables 1-8.

\section{Results and Discussions}

In this study the MHD Free Convection and Mass Transfer Flow of Viscous Incompressible Fluid about an Table 1. Numerical values of Skin friction coefficient $\tau_{x}, \tau_{w}$, Nusselt number $N_{u}$ and Sherwood $S_{h}$ for different values of $f_{w}$, taking $\gamma=60^{\circ}, G_{r}=4, G_{m}=2, \quad M=0.5, \quad m=0.01, P_{r}=0.71, E_{c}=0.01, S_{c}=0.6$ as fixed.

\begin{tabular}{ccccc}
\hline$f_{w}$ & $\tau_{x}$ & $\tau_{w}$ & $N_{u}$ & $S_{h}$ \\
-2.5 & 0.6668289 & 0.0004485 & -8.8553316 & 0.0084551 \\
-2.0 & 0.6287051 & 0.0005869 & -6.9865942 & 0.0178285 \\
-1.5 & 0.5931507 & 0.0007727 & -5.4077292 & 0.0368737 \\
-1.0 & 0.5585643 & 0.0009901 & -4.1194896 & 0.0741882 \\
-0.5 & 0.5191494 & 0.0011747 & -3.1007791 & 0.1427078 \\
0.0 & 0.4644253 & 0.0012120 & -2.3082940 & 0.2573300 \\
0.5 & 0.3853305 & 0.0010154 & -1.6914004 & 0.4284642 \\
1.0 & 0.2902217 & 0.0006616 & -1.2231636 & 0.6558428 \\
1.5 & 0.2076919 & 0.0003625 & -0.9004500 & 0.9235492 \\
2.0 & 0.1512463 & 0.0001927 & -0.6940337 & 1.2113470 \\
2.5 & 0.1151882 & 0.0001083 & -0.5600067 & 1.5061140 \\
\hline
\end{tabular}

Table 2. Numerical values of Skin friction coefficient $\tau_{x}, \tau_{w}$, Nusselt number $N_{u}$ and Sherwood $S_{h}$ for different values of $M$, taking $f_{w}=0.5, \quad \gamma=60^{\circ}, G_{r}=4, \quad G_{m}=2, \quad m=0.01, \quad P_{r}=0.71, \quad E_{c}=0.01, S_{c}=0.6$ as fixed.

\begin{tabular}{ccccc}
$M$ & $\tau_{x}$ & $\tau_{w}$ & $N_{u}$ & $S_{h}$ \\
\hline 0.0 & 1.1932292 & 0.0000000 & -1.2511745 & 0.5666003 \\
0.1 & 1.1505234 & 0.0006646 & -1.2670365 & 0.5586785 \\
0.5 & 1.0120026 & 0.0021178 & -1.3286136 & 0.5313269 \\
0.9 & 0.9125222 & 0.0026414 & -1.3847014 & 0.5096192 \\
1.3 & 0.8378965 & 0.0028195 & -1.4353510 & 0.4921174 \\
1.7 & 0.7796588 & 0.0028587 & -1.4811938 & 0.4777218 \\
2.0 & 0.7436022 & 0.0028472 & -1.5128227 & 0.4684503 \\
2.4 & 0.7029445 & 0.0028058 & -1.5518709 & 0.4577611 \\
\hline
\end{tabular}


Table 3. Numerical values of Skin friction coefficient $\tau_{x}, \tau_{w}$, Nusselt number $N_{u}$ and Sherwood $S_{h}$ for different values of $E_{c}$, taking $f_{w}=0.5, \gamma=60^{\circ}, G_{r}=4, G_{m}=2, \quad m=0.01, \quad P_{r}=0.71, \quad M=0.5, S_{c}=0.6$ as fixed.

\begin{tabular}{ccccc}
\hline & $\tau_{x}$ & $\tau_{w}$ & $N_{u}$ & $S_{h}$ \\
\hline 0.01 & 1.0092523 & 0.0021140 & -1.3092204 & 0.5309962 \\
0.2 & 1.0150838 & 0.0021221 & -1.3503572 & 0.5316967 \\
0.5 & 1.0244907 & 0.0021350 & -1.4168547 & 0.5328213 \\
0.8 & 1.0341510 & 0.0021481 & -1.4853229 & 0.5339694 \\
1.0 & 1.0407378 & 0.0021571 & -1.5321099 & 0.5347483 \\
2.0 & 1.0755707 & 0.0022038 & -1.7809118 & 0.5388165 \\
3.0 & 1.1139666 & 0.0022543 & -2.0577948 & 0.5432046 \\
\hline
\end{tabular}

Table 4. Numerical values of Skin friction coefficient $\tau_{x}, \tau_{w}$, Nusselt number $N_{u}$ and Sherwood $S_{h}$ for different values of $P_{r}$, taking $f_{w}=0.5, \quad \gamma=60^{\circ}, \quad G_{r}=4, G_{m}=2, \quad m=0.01, \quad S_{c}=0.6, \quad M=0.5, \quad E_{c}=0.01$ as fixed.

\begin{tabular}{ccccc}
\hline$P_{r}$ & $\tau_{x}$ & $\tau_{w}$ & $N_{u}$ & $S_{h}$ \\
0.2 & 3.4971321 & 0.0054212 & -1.8970950 & 0.7623321 \\
0.5 & 2.4064302 & 0.0035968 & -1.3401110 & 0.6562548 \\
0.73 & 2.0548293 & 0.0030741 & -1.1387300 & 0.6180418 \\
2.0 & 1.3704993 & 0.0022716 & -0.6750511 & 0.5476207 \\
3.0 & 1.1933258 & 0.0021228 & -0.5234823 & 0.5329146 \\
4.0 & 1.0984838 & 0.0020532 & -0.4305351 & 0.5261758 \\
\hline
\end{tabular}

Table 5. Numerical values of Skin friction coefficient $\tau_{x}, \tau_{w}$, Nusselt number $N_{u}$ and Sherwood $S_{h}$ for different values of $S_{c}$, taking $f_{w}=0.5, \quad \gamma=60^{\circ}, G_{r}=4, \quad G_{m}=2, \quad m=0.01, \quad P_{r}=0.71, \quad M=0.5, \quad E_{c}=0.01$ as fixed.

\begin{tabular}{ccccc}
\hline$S_{c}$ & $\tau_{x}$ & $\tau_{w}$ & $N_{u}$ & $S_{h}$ \\
\hline 0.1 & 2.2727114 & 0.0046670 & -1.0157428 & 0.2099315 \\
0.5 & 2.0455986 & 0.0031604 & -1.0939712 & 0.5470686 \\
0.6 & 2.0206484 & 0.0030510 & -1.1038032 & 0.6158846 \\
1.0 & 1.9525342 & 0.0028277 & -1.1296907 & 0.8666338 \\
2.0 & 1.8621742 & 0.0026558 & -1.1585317 & 1.4158038 \\
3.0 & 1.8106484 & 0.0025966 & -1.1714276 & 1.9240325 \\
\hline
\end{tabular}

Table 6. Numerical values of Skin friction coefficient $\tau_{x}, \tau_{w}$, Nusselt number $N_{u}$ and Sherwood $S_{h}$ for different values of $\gamma$, taking $f_{w}=0.5, \quad G_{r}=4, \quad G_{m}=2, \quad m=0.01, \quad P_{r}=0.71, \quad M=0.5, \quad E_{c}=0.01, \quad S_{c}=0.6$ as fixed.

\begin{tabular}{ccccc}
\hline$\gamma$ & $\tau_{x}$ & $\tau_{w}$ & $N_{u}$ & $S_{h}$ \\
\hline $0^{\circ}$ & 3.2825601 & 0.0039806 & -0.9686241 & 0.6969894 \\
$30^{\circ}$ & 2.9778622 & 0.0037784 & -0.9941611 & 0.6795973 \\
$45^{\circ}$ & 2.5835102 & 0.0035011 & -1.0328613 & 0.6551832 \\
$60^{\circ}$ & 2.0206484 & 0.0030510 & -1.1038032 & 0.6158846 \\
$80^{\circ}$ & 0.9409304 & 0.0019090 & -1.3532552 & 0.5141570 \\
\hline
\end{tabular}


Table 7. Numerical values of Skin friction coefficient $\tau_{x}, \tau_{w}$, Nusselt number $N_{u}$ and Sherwood $S_{h}$ for different values of $G_{r}$, taking $f_{w}=0.5, \quad \gamma=60^{\circ}, \quad P_{r}=0.71, G_{m}=2, \quad m=0.01, \quad S_{c}=0.6, \quad M=0.5, \quad E_{c}=0.01$ as fixed.

\begin{tabular}{ccccc}
\hline$G_{r}$ & $\tau_{x}$ & $\tau_{w}$ & $N_{u}$ & $S_{h}$ \\
\hline 1.0 & 1.7983003 & 0.0029964 & -1.1233734 & 0.6084964 \\
2.0 & 2.0536032 & 0.0031933 & -1.0878147 & 0.6260093 \\
3.0 & 2.2878734 & 0.0033582 & -1.0594478 & 0.6411855 \\
4.0 & 2.5072444 & 0.0035082 & -1.0357385 & 0.6544944 \\
5.0 & 2.7144836 & 0.0036432 & -1.0155186 & 0.6664838 \\
\hline
\end{tabular}

Table 8. Numerical values of Skin friction coefficient $\tau_{x}, \tau_{w}$, Nusselt number $N_{u}$ and Sherwood $S_{h}$ for different values of $G_{m}$, taking $f_{w}=0.5, \quad \gamma=60^{\circ}, P_{r}=0.71, G_{r}=4, \quad m=0.01, \quad S_{c}=0.6, \quad M=0.5, \quad E_{c}=0.01$ as fixed.

\begin{tabular}{ccccc}
\hline$G_{m}$ & $\tau_{x}$ & $\tau_{w}$ & $N_{u}$ & $S_{h}$ \\
\hline 1.0 & 1.7760922 & 0.0027873 & -1.1479420 & 0.5935038 \\
2.0 & 2.0206484 & 0.0030510 & -1.1038032 & 0.6158846 \\
3.0 & 2.2646066 & 0.0032880 & -1.0670246 & 0.6361347 \\
4.0 & 2.5072444 & 0.0035082 & -1.0357385 & 0.6544944 \\
5.0 & 2.7474932 & 0.0037103 & -1.0088037 & 0.6713796 \\
\hline
\end{tabular}

inclined Plate with Hall Current and Constant Heat Flux have been investigated using the Nachtsheim-Swigert shooting iteration technique. To study the physical situation of this problem, we have computed the numerical values of the velocity, temperature, and concentration within the boundary layer and also find the skin friction coefficient, Nusseltnumber, Sherwood number at the plate. It can be seen that the solutions are affected by the parameters, namely suction parameter $f_{w}$, Grashof number $G_{r}$, modified Grashof number $G_{m}$, magnetic parameter $M$, Prandtl number $P_{r}$, Eckert number $E_{c}$, Schimidt number. The values of $M$ and $G_{r}$ are taken to be large for cooling Newtonian fluid keeping the plate at different angle. The values $0.2,0.5,0.73,2$, 3, 4, 5 are considered for $P_{r}$. The values $0.1,0.5,0.6,1.0,2.0,3.0,4.0$ also considered for $S_{c}$. The values of other parameters are however chosen arbitrarily.

Figures 2-5, respectively, show the primary velocity, secondary velocity, temperature and concentration profiles for different values of suction parameter $f_{w}$. Here $f_{w}>0$ corresponds to suction and $f_{w}<0$ corresponds to injection at the plate or blowing. From Figure 2-5, it can be seen that the primary velocity, secondary velocity, temperature and concentration profiles decreases with the increase of suction parameter $f_{w}$. Figures 6-9, respectively, show the primary velocity, secondary velocity profiles decreased and temperature and concentration profiles increases for different values of $M$. Figure 10 \& Figure 11, respectively, show the cross-flow of primary velocity and secondary velocity, at first increases then decreases with the increase of $E_{c}$. Figure 12 \& Figure 13 shows that the temperature profile increase and concentration profile decreases with the increase of $E_{c}$. Figures 14-17 show that the primary velocity, secondary velocity profile and concentration profile decreases and temperature profile increases with the increase of $S_{c}$. Figure 18 \& Figure 19 , respectively, shows the cross flow of the primary velocity and secondary velocity with the increase of $P_{r}$ both of the profile is decrease then increase. Figure 20 \& Figure 21 shows that temperature decrease and concentration profile increase with the increase of $S_{c}$. Figure 22 \& Figure 23, show the cross flow of the primary velocity and secondary velocity with the increase of $\gamma$ both of the profile is decrease then increase. Figure 24 \& Figure 25, show that temperature and concentration profile increases with the increase of $\gamma$. Figure 26 \& Figure 27, show the cross flow of the primary velocity and secondary velocity with the increase of $G_{r}$. Figure 28 \& Figure 29, shows that the temperature and concentration profile decreases with the increase of $G_{r}$. Figure 30 \& Figure 31, show the cross flow of the primary velocity and secondary velocity with the increase of $G_{m}$. Figure 32 \& Figure 33, shows that the temperature and concentration profile decreases 


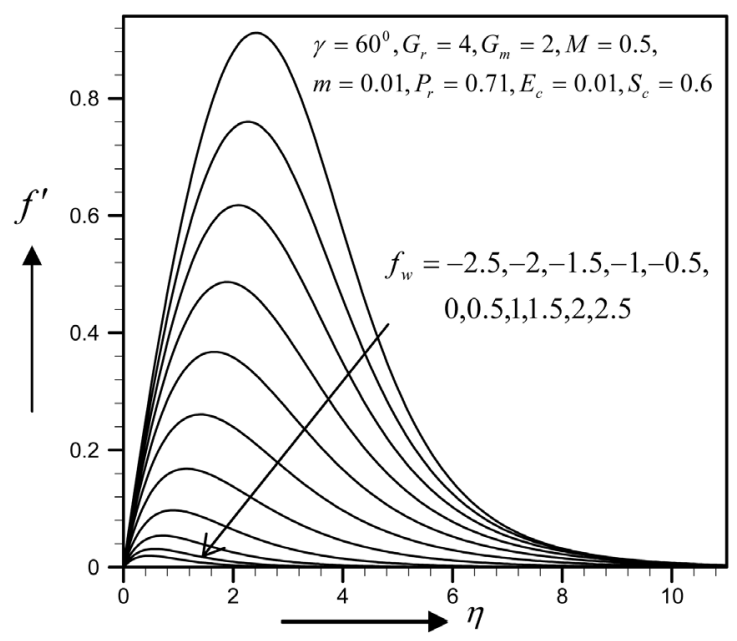

Figure 2. Primary velocity profile for $f_{w}$.

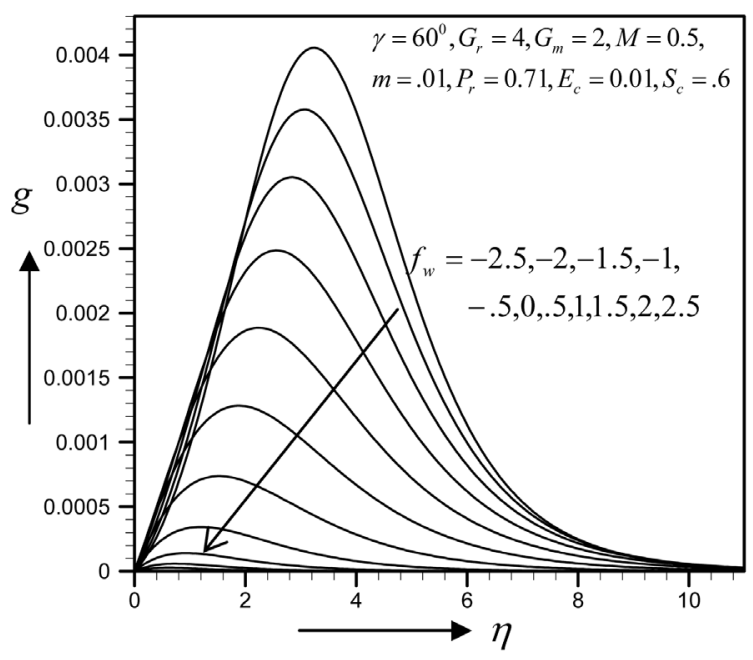

Figure 3. Secondary velocity profile for $f_{w}$.

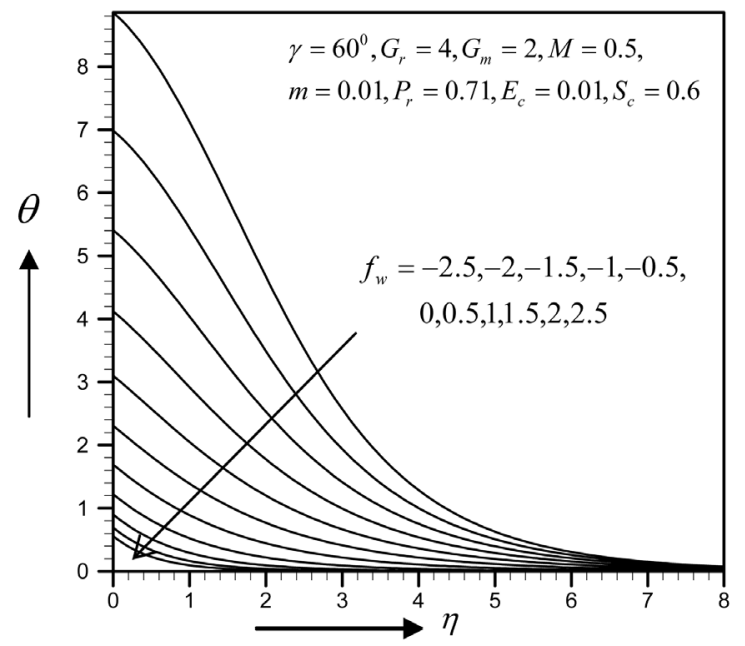

Figure 4. Temperature profile for $f_{w}$. 


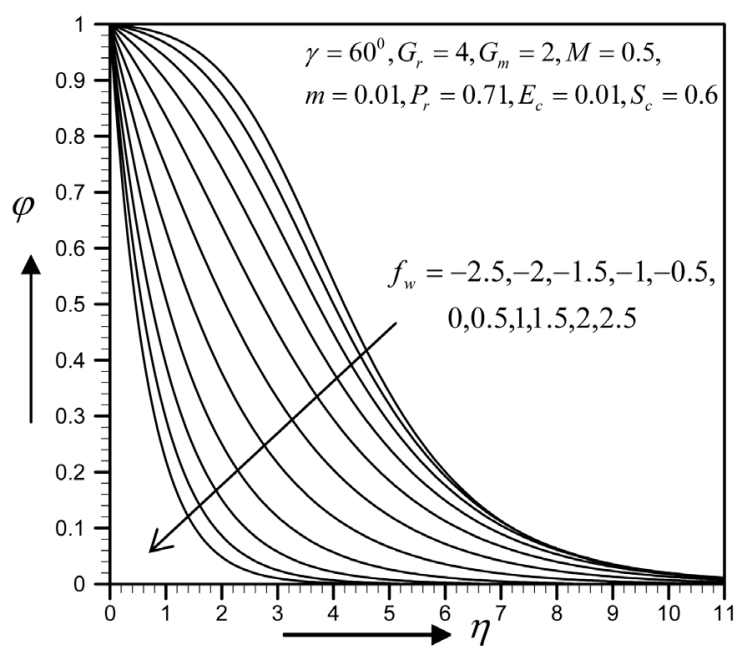

Figure 5. Concentration profile for $f_{w}$.

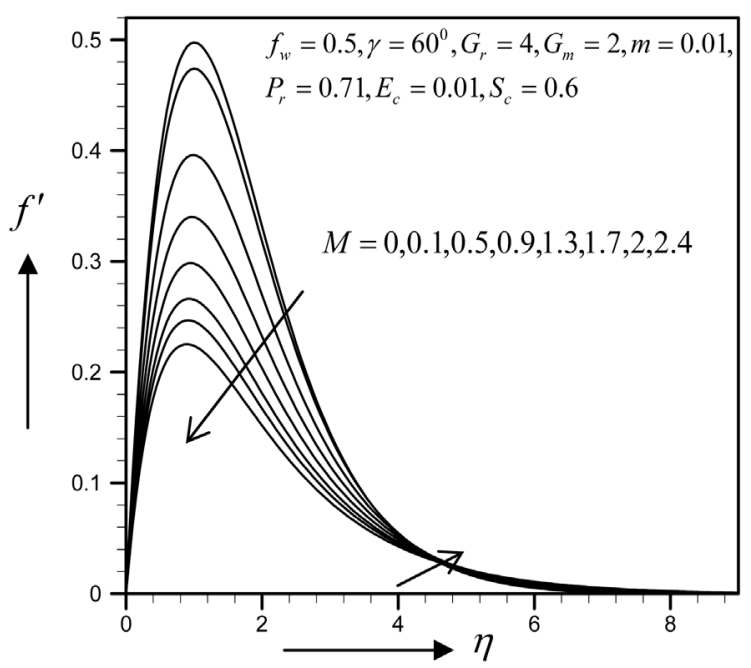

Figure 6. Primary velocity profile for $M$.

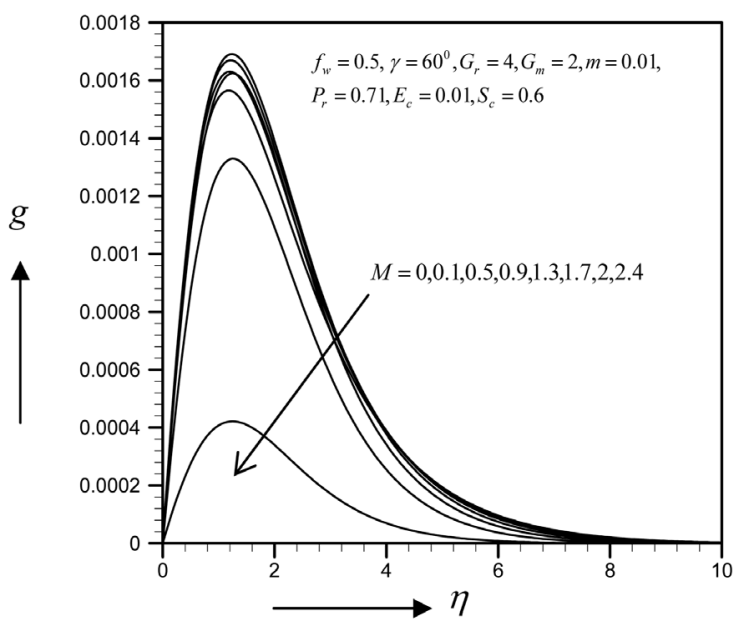

Figure 7. Secondary velocity profile $M$. 


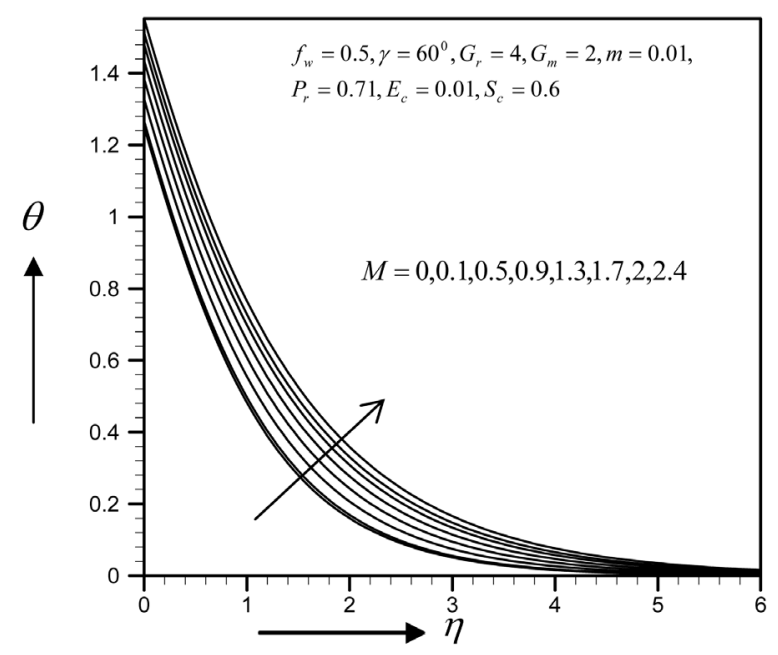

Figure 8. Temperature profile for $M$.

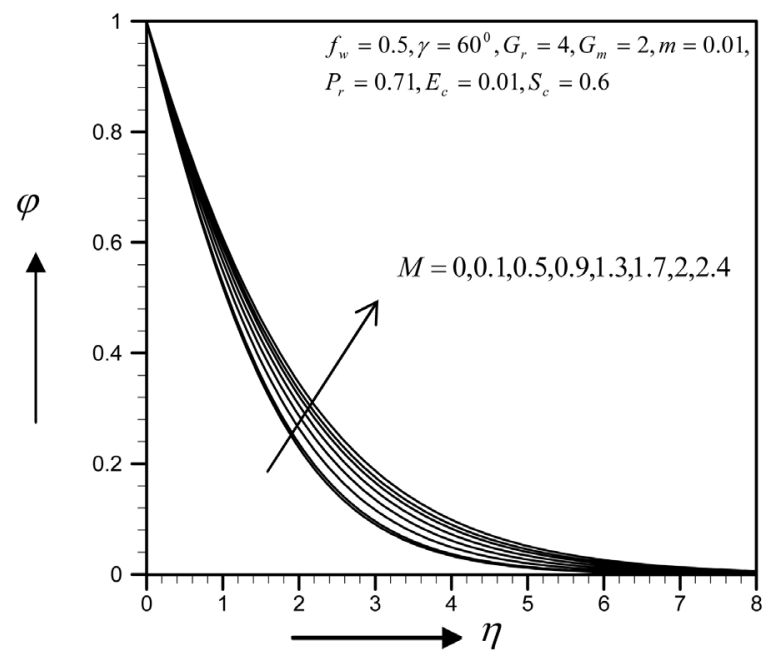

Figure 9. Concentration profile for $M$.

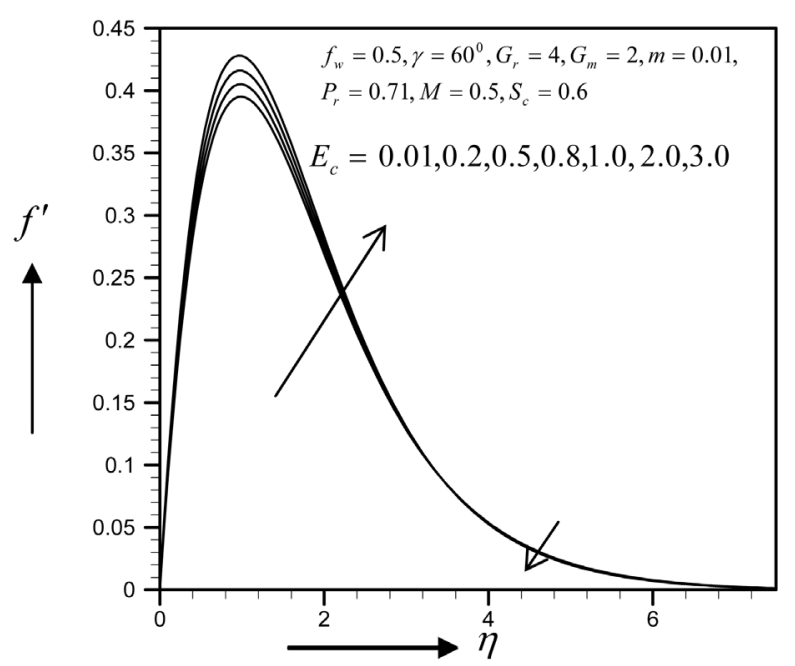

Figure 10. Primary velocity profile for $E_{c}$. 


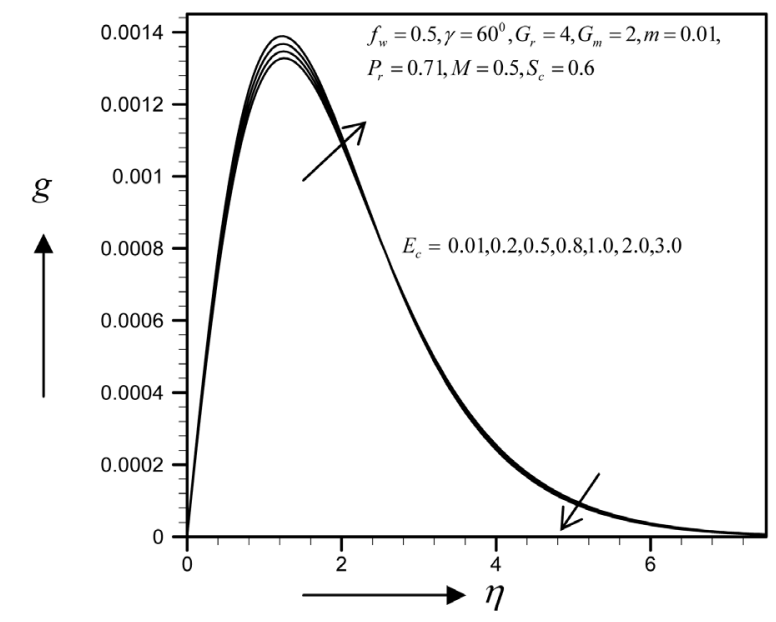

Figure 11. Secondary velocity profile $E_{c}$.

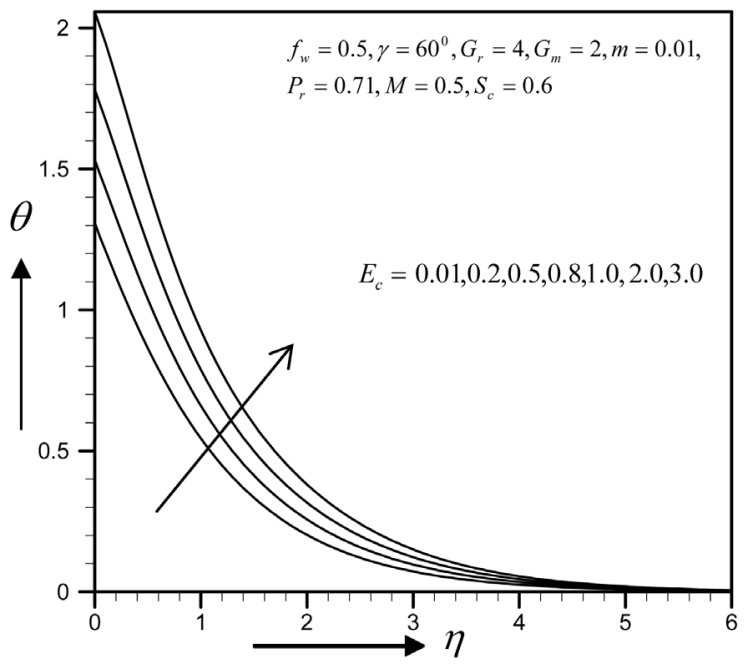

Figure 12. Temperature profile for $E_{c}$.

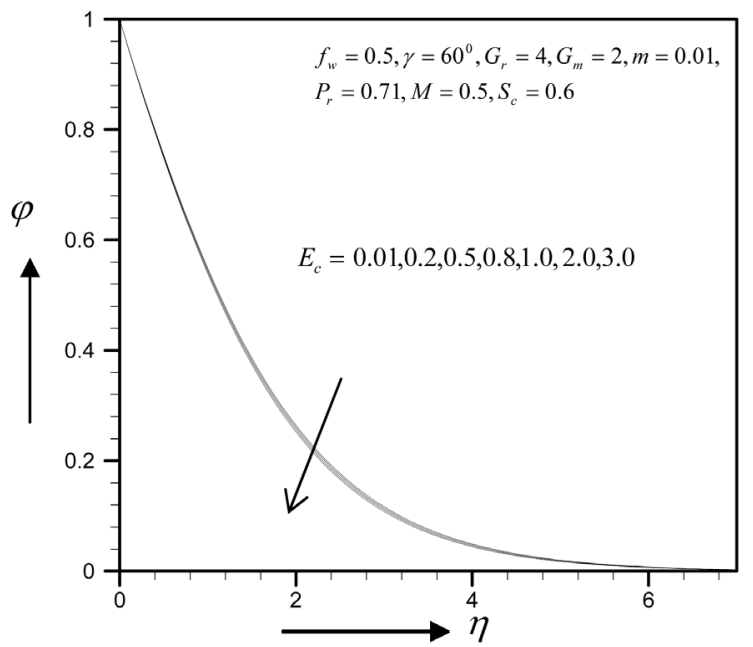

Figure 13. Concentration profile for $E_{c}$. 


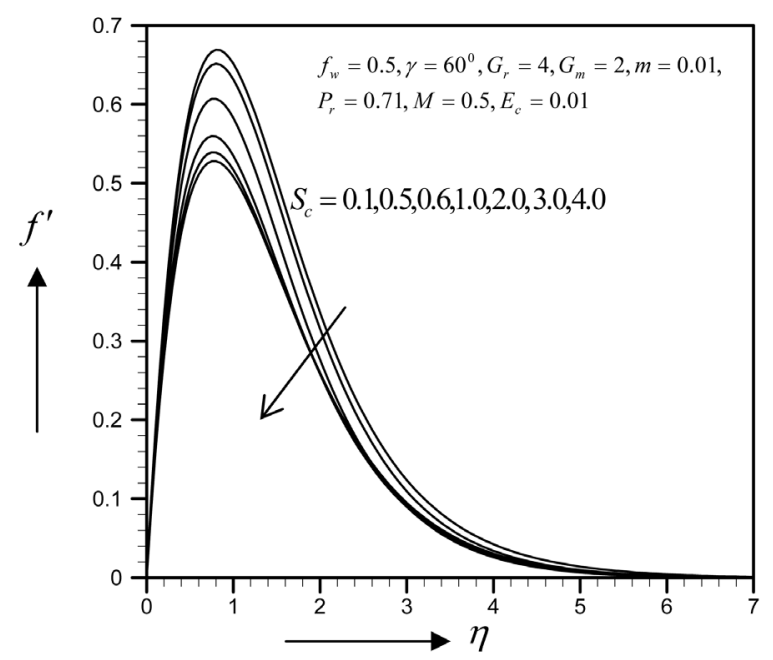

Figure 14. Primary velocity profile for $S_{c}$.

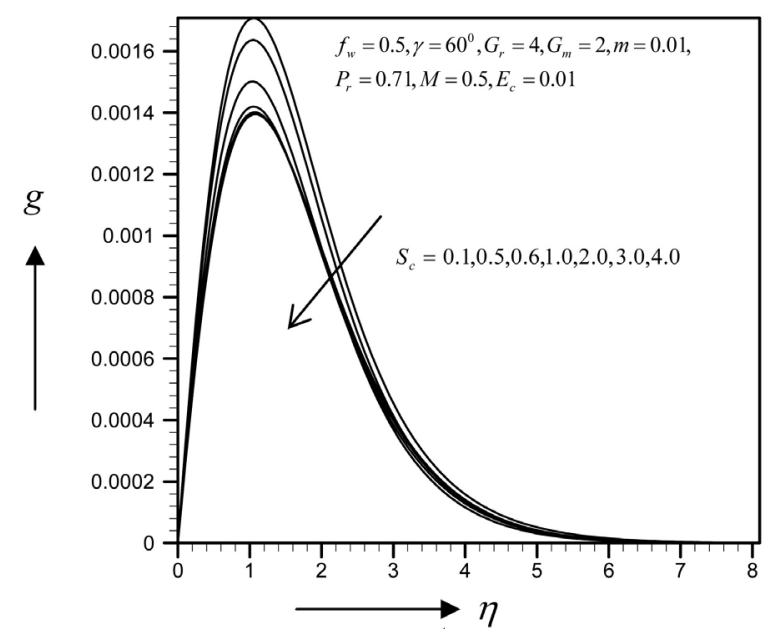

Figure 15. Secondary velocity profile for $S_{c}$.

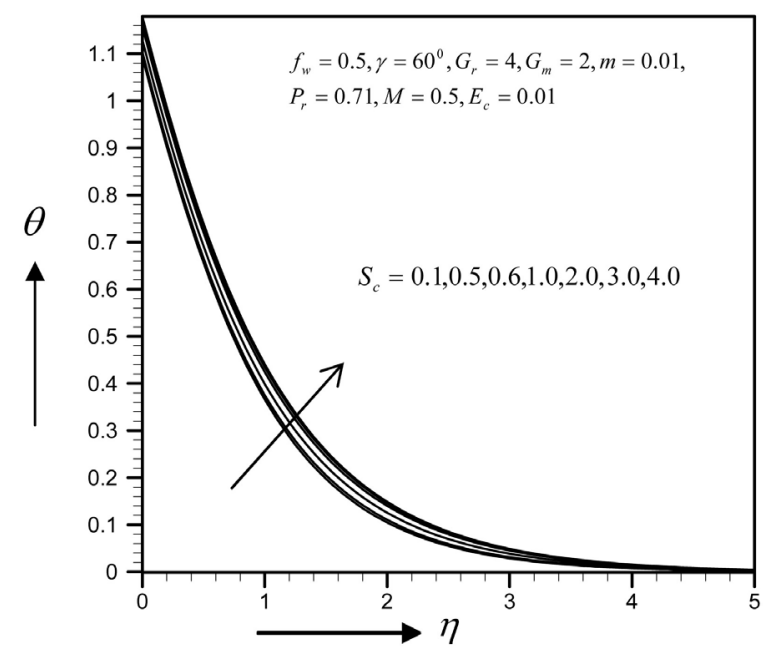

Figure 16. Temperature profile for $S_{c}$. 


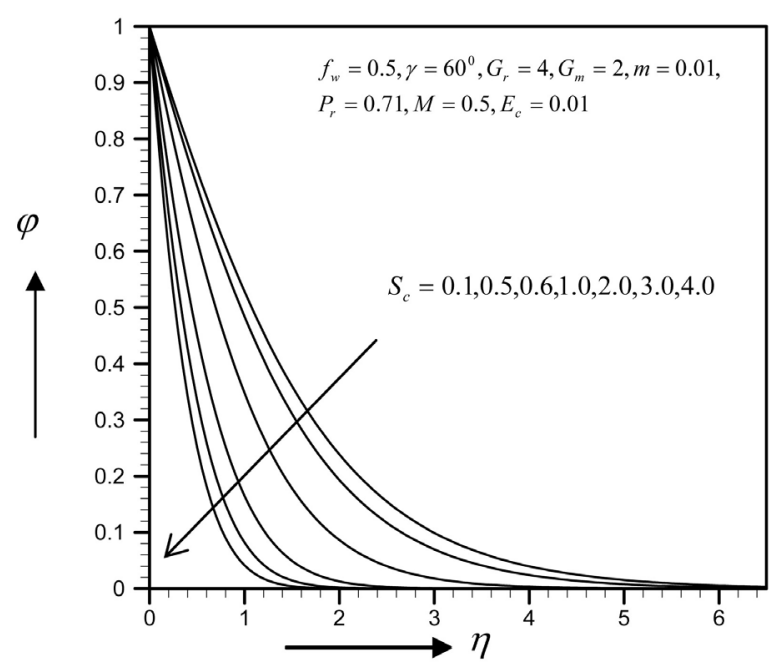

Figure 17. Concentration profile for $S_{c}$.

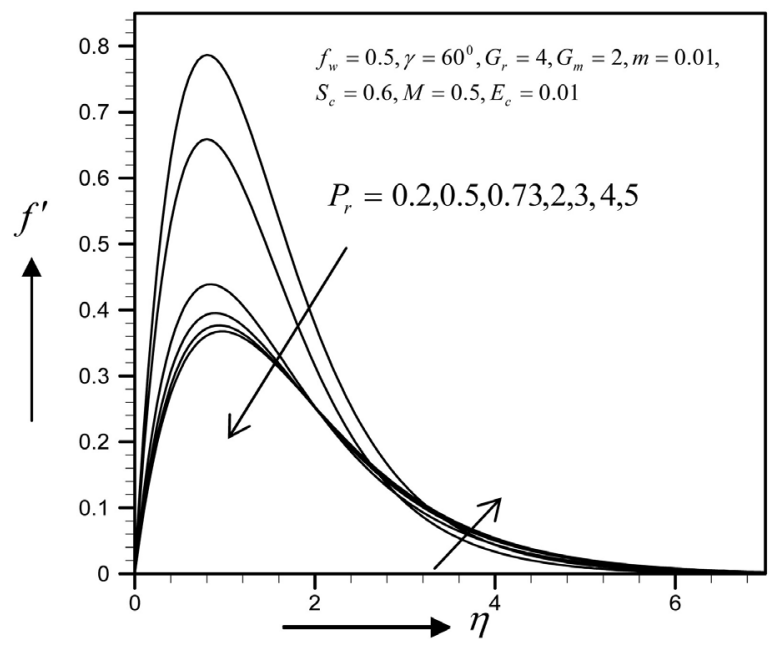

Figure 18. Primary velocity profile $P_{r}$.

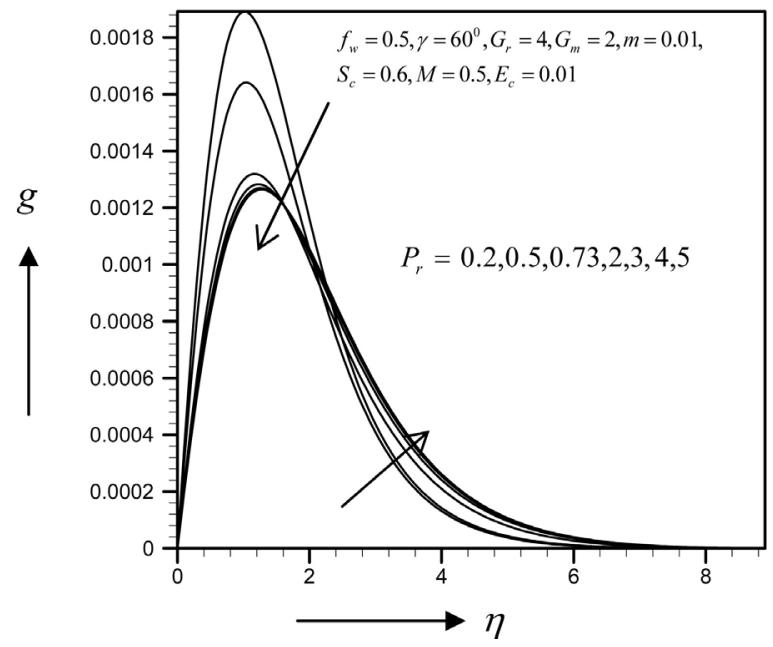

Figure 19. Secondary velocity profile $P_{r}$. 


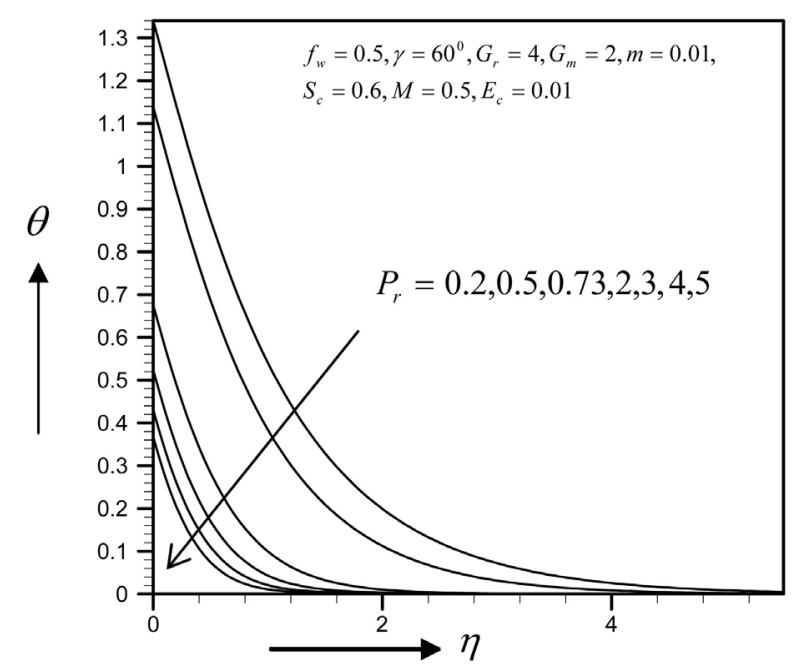

Figure 20. Temperature profile for $P_{r}$.

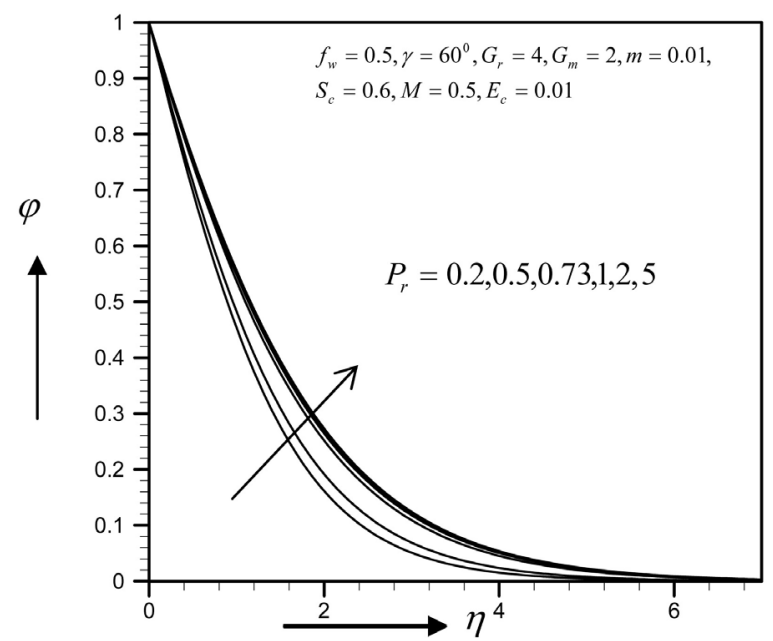

Figure 21. Concentration profile for $P_{r}$.

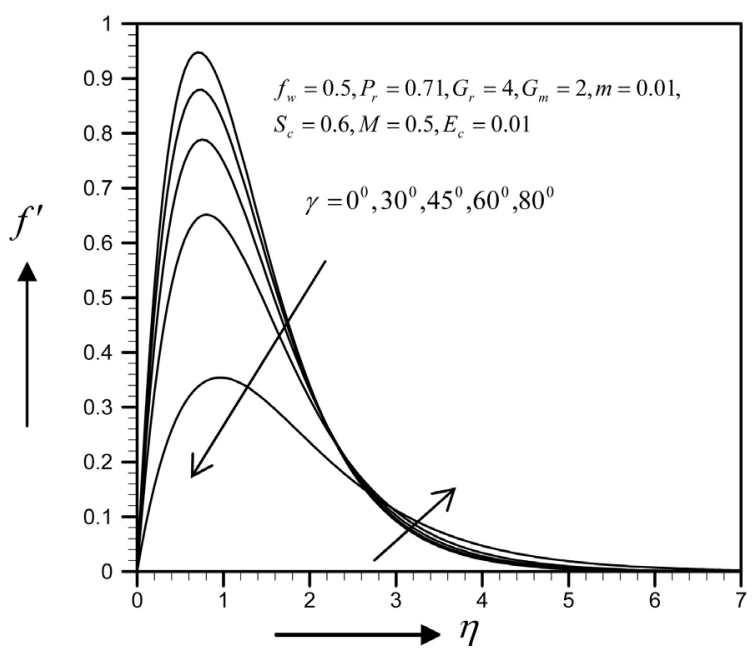

Figure 22. Primary velocity profile for $\gamma$. 


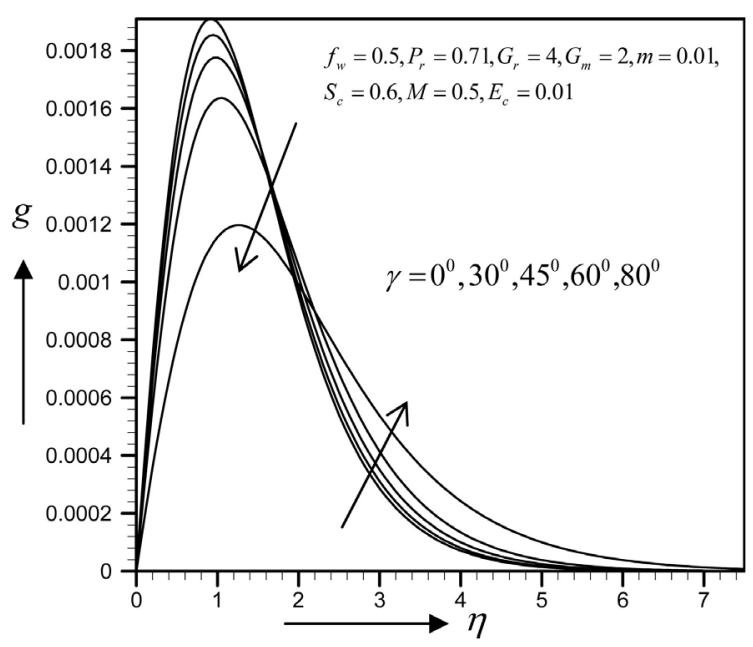

Figure 23. Secondary velocity profile for $\gamma$.

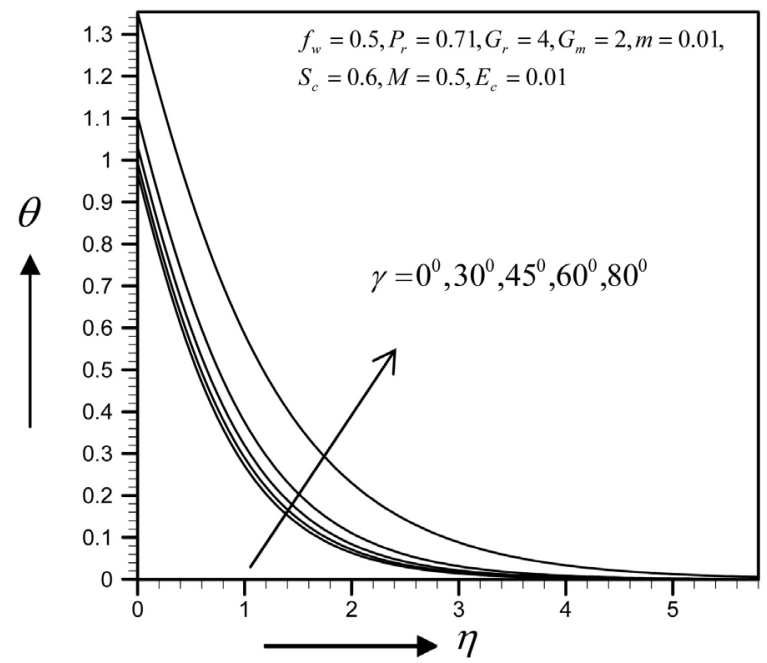

Figure 24. Temperature profile for $\gamma$.

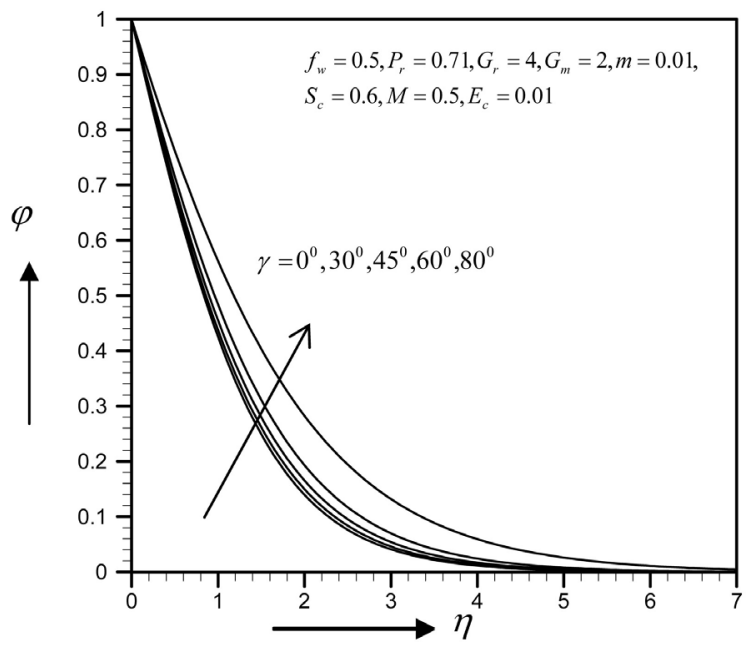

Figure 25. Concentration profile for $\gamma$. 
M. Wahiduzzaman et al.

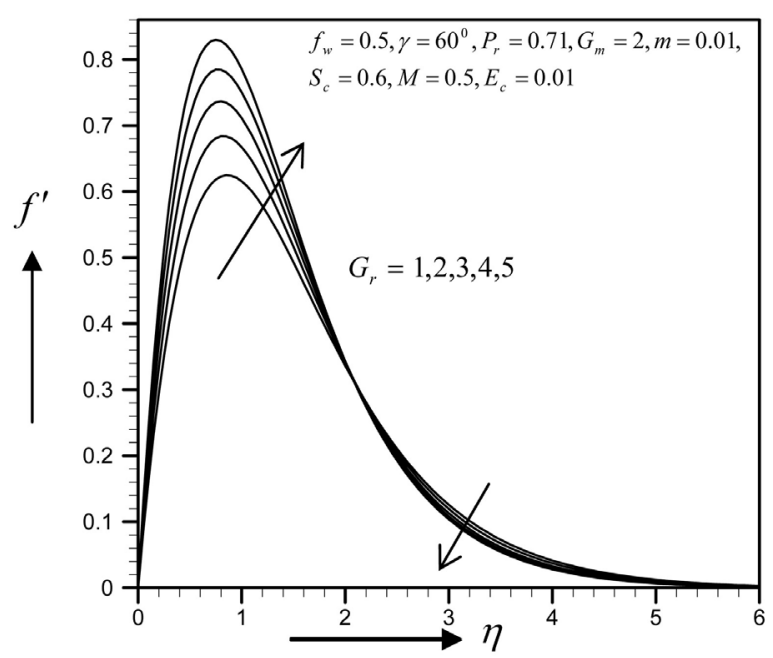

Figure 26. Primary velocity profile for $G_{r}$.

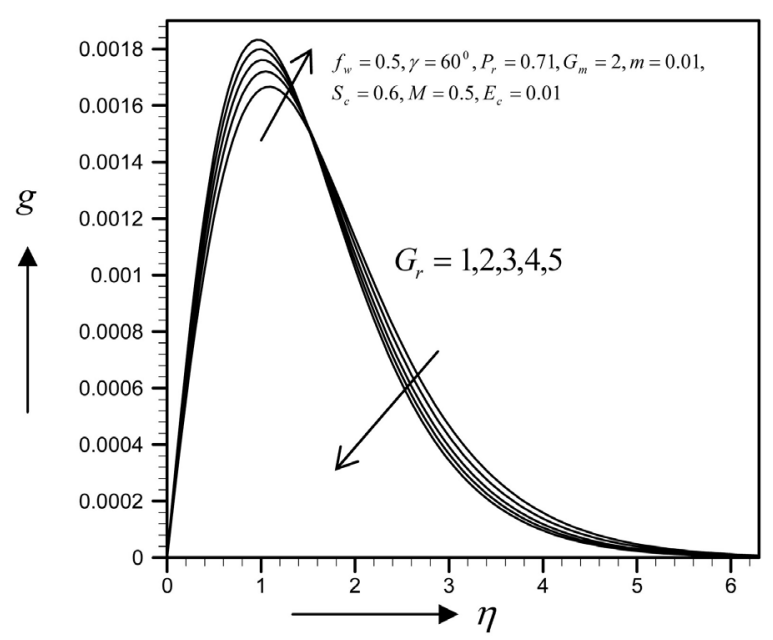

Figure 27. Secondary velocity profile for $G_{r}$.

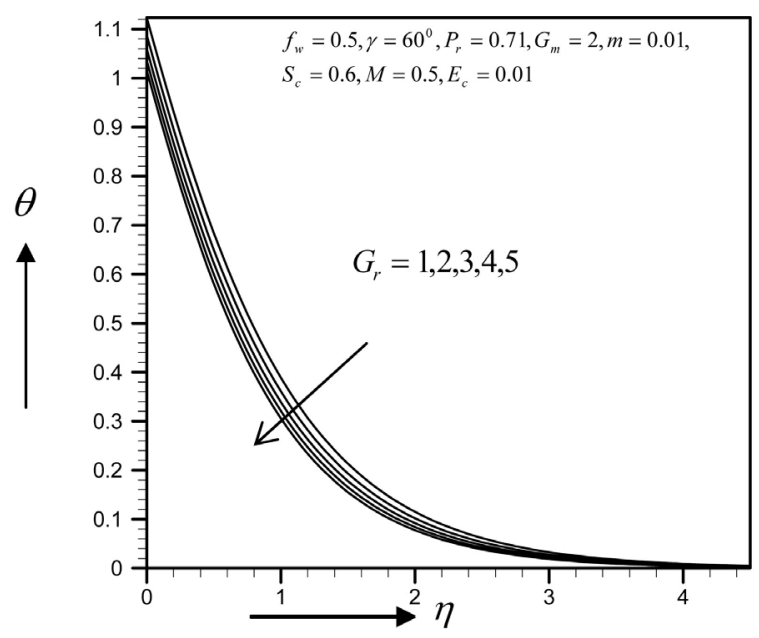

Figure 28. Temperature profile for $G_{r}$.

1703 
M. Wahiduzzaman et al.

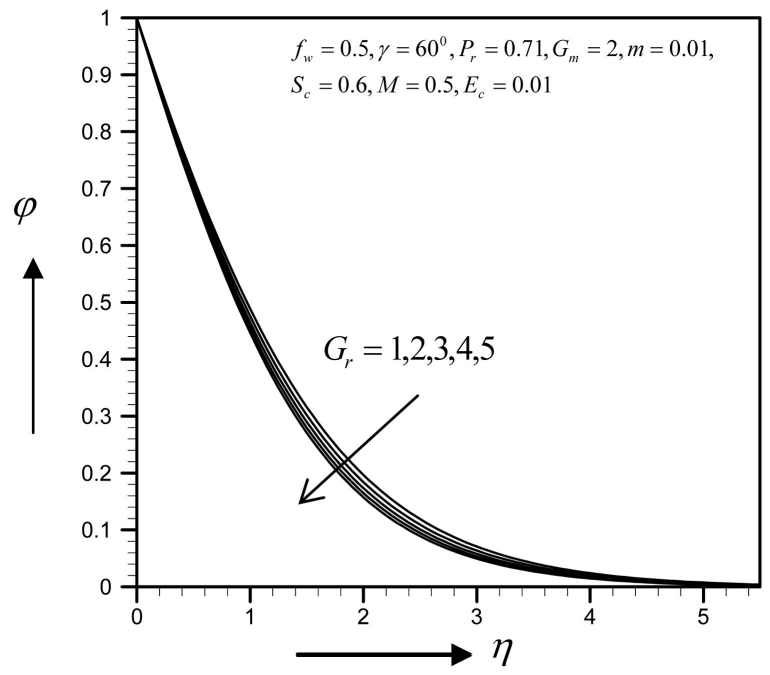

Figure 29. Concentration profile for $G_{r}$.

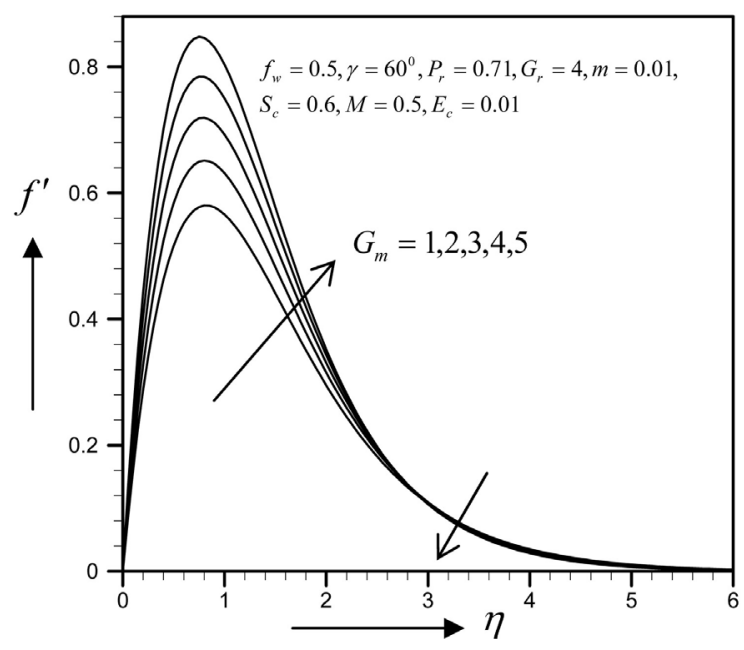

Figure 30. Primary velocity profile for $G_{m}$.

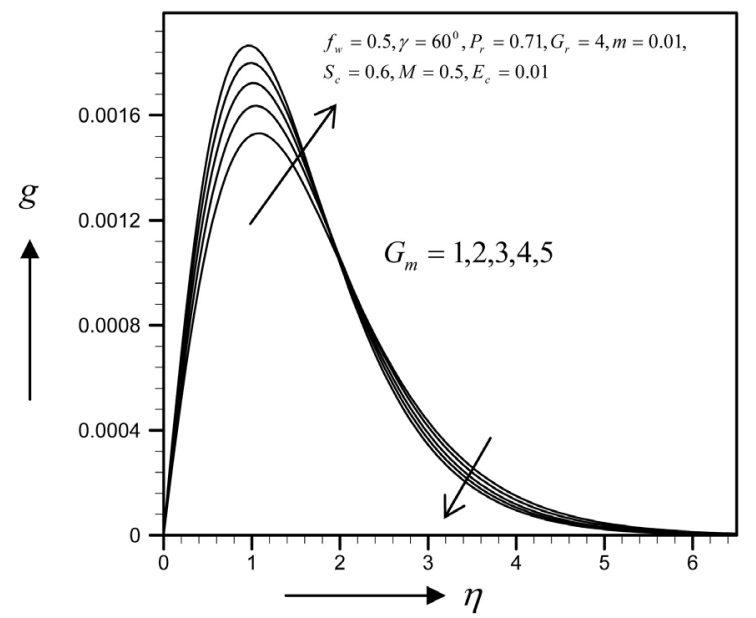

Figure 31. Secondary velocity profile for $G_{m}$.

1704 


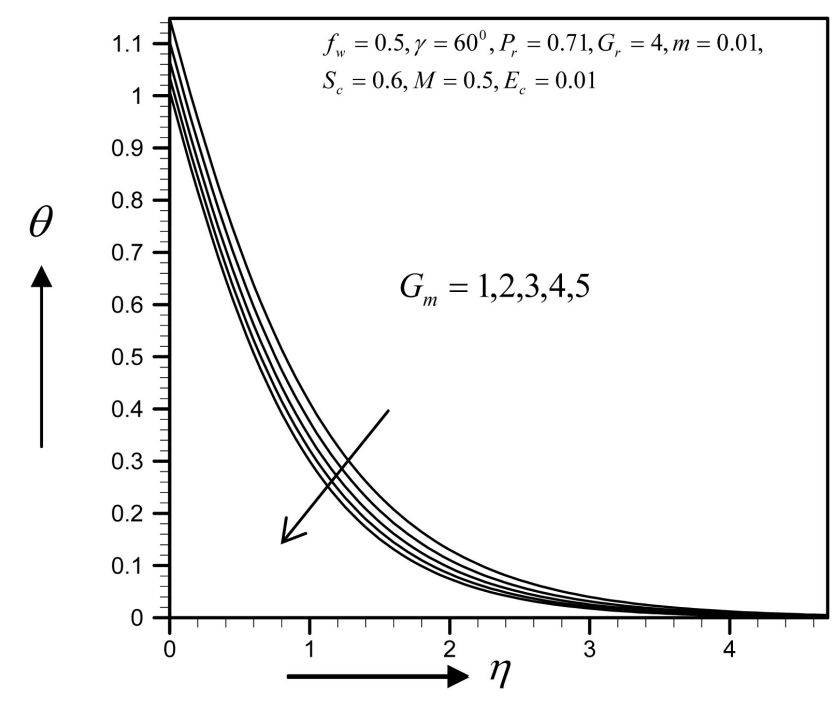

Figure 32. Temperature profile for $G_{m}$.

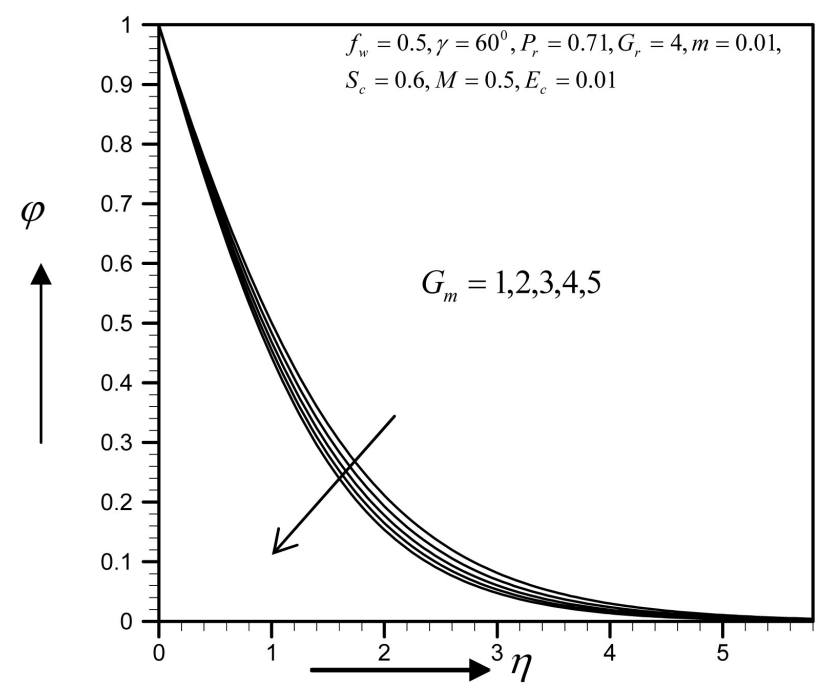

Figure 33. Concentration profile for $G_{m}$.

with the increase of $G_{m}$.

From Figure 34-37, show the velocity, secondary velocity, temperature and concentration profile field has a negligible effect for different values of $m$.

Finally the effect of various parameters on the skin friction coefficients $\left(\tau_{x}, \tau_{w}\right)$, Nusselt number $\left(N_{u}\right)$ and Sherwood $\left(S_{h}\right)$ are tabulated in Tables 1-8. Table 1 shows that the skin friction coefficient $\left(\tau_{x}, \tau_{w}\right)$ decreases and Nusselt number $\left(N_{u}\right)$ and Sherwood number $\left(S_{h}\right)$ increase with the increase of $f_{w}$. Table 2 shows that the skin friction coefficient $\tau_{x}$ decreases and $\tau_{w}$ increases and Nusselt number $\left(N_{u}\right)$ and Sherwood number $\left(S_{h}\right)$ decreases with the increase of $M$. Table 3 shows that the skin friction coefficient $\left(\tau_{x}, \tau_{w}\right)$ and Sherwood number $\left(S_{h}\right)$ increases and Nusselt number $\left(N_{u}\right)$ decreases with the increase of $E_{c}$. Table 4 shows that the skin friction coefficient $\left(\tau_{x}, \tau_{w}\right)$ and Sherwood number $\left(S_{h}\right)$ decreases and Nusselt number $\left(N_{u}\right)$ increases with the increase of $P_{r}$. Table 5 shows that the skin friction coefficient $\left(\tau_{x}, \tau_{w}\right)$ and Nusselt number $\left(N_{u}\right)$ decreases and Sherwood number $\left(S_{h}\right)$ increases with the increase of $S_{c}$. Table 6 shows that the skin friction coefficients $\left(\tau_{x}, \tau_{w}\right)$, Nusselt number $\left(N_{u}\right)$ and Sherwood number $\left(S_{h}\right)$ decreases with the increase of $\gamma$. Table $7 \&$ Table 8 shows that the skin friction coefficients $\left(\tau_{x}, \tau_{w}\right)$, Nusselt number $\left(N_{u}\right)$ and Sherwood number $\left(S_{h}\right)$ increases with the increase of $G_{r}$ and $G_{m}$. 


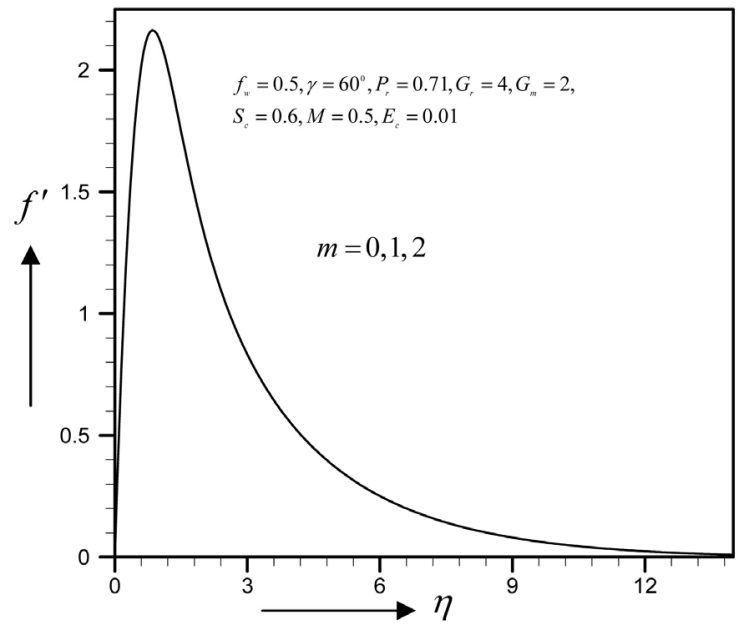

Figure 34. Primary velocity profile for $m$.

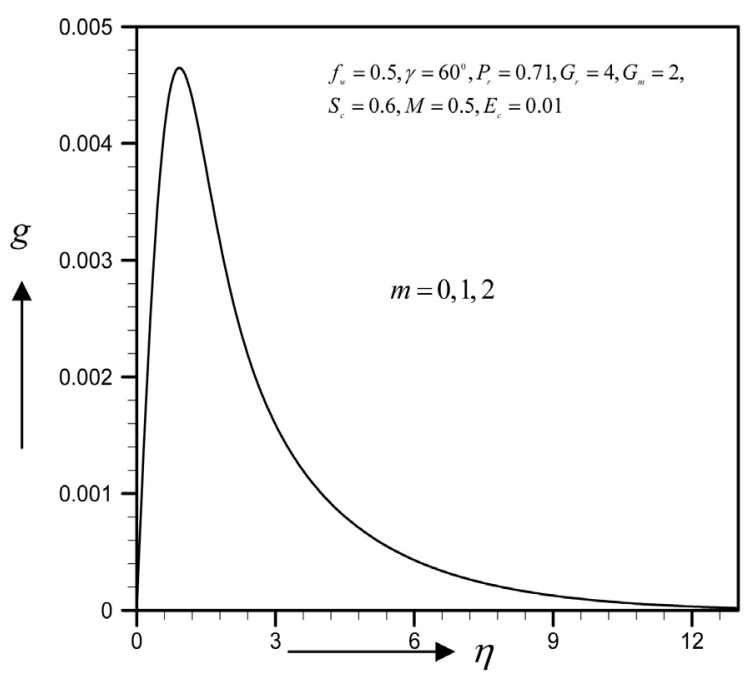

Figure 35. Secondary velocity profile for $m$.

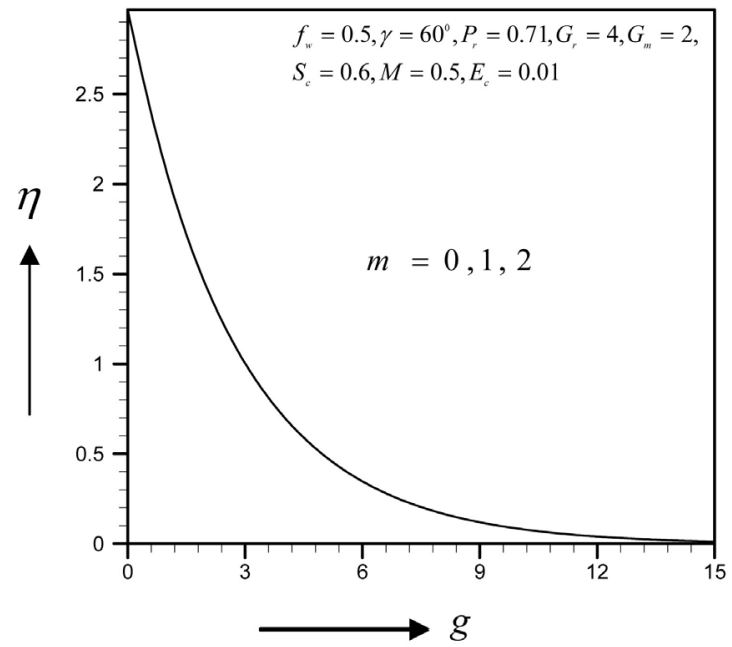

Figure 36. Temperature profile for $m$. 


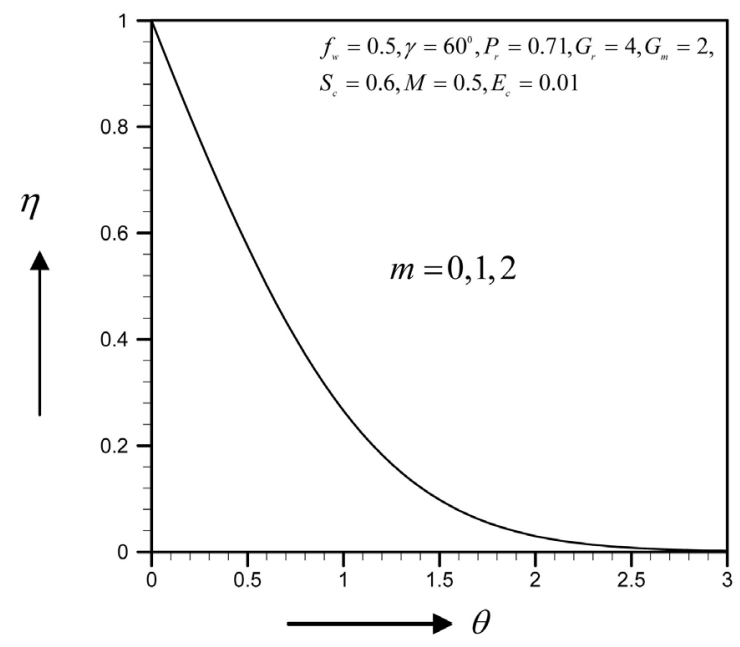

Figure 37. Concentration profile for $m$.

\section{Conclusions}

The effect of viscous incompressible fluid flow about an inclined plate with hall current is analyzed in the present study for constant heat flux. A range of physical parameter values tested over the boundary layer flows. The variation of different physical parameters instigated different flow pattern as increasing, decreasing and cross flow in the dimensionless primary and secondary velocity, temperature and concentration distribution as well as in the profile of skin friction coefficients, Nusseltand Sherwood number. The findings of the present investigation are briefly:

- As suction parameter increases, the primary velocity, secondary velocity, temperature and concentration profiles decrease gradually. However for the same parameter effects, the skin friction coefficient decreases and Nusselt and Sherwood numbers increase.

- The primary velocity, secondary velocity profiles as well as the skin friction coefficient, Nusselt and Sherwood numbers decreased as magnetic parameter increased whereas the reverse effects found in the profile of temperature and concentration.

- The cross-flow of primary and secondary velocity observed as Eckert number increases whereas temperature profile increases and concentration profile decreases for the same parameter effects. Also for the similar parameter effects skin friction coefficient and Sherwood number increase whereas Nusselt number decreases.

- The increasing effect of Schmidt number causes primary and secondary velocity profile and concentration profile as well as the skin friction coefficient and Nusselt number decrease whereas the reverse situation observed in the temperature and Sherwood number profiles.

- The cross flow of the primary and secondary velocity with the increase of Prandlt number has been observed, where both of the profiles first decrease and near the layer the profiles increase. However within the same parameter effects, the skin friction coefficient and Sherwood number decrease and Nusselt number increases.

- As the parameter $\gamma$ rises the cross flow pattern observed in primary and secondary velocity profiles whereas temperature and concentration profile increase. However for the same parameter effects the skin friction coefficient, Nusselt number and Sherwood number profiles decrease.

- The increasing effect of Grashof and modified Grashof number causes the cross flow of the primary and secondary velocity whereas temperature and concentration profile decrease for the similar parameter effects. However the skin friction coefficient, Nusselt number and Sherwood number increase.

\section{References}

[1] Sato, H. (1961) The Hall Effect in the Viscous Flow of Ionized Gas between Two Parallel Plates under Transverse Magnetic Field. Journal of the Physical Society of Japan, 16, 1427-1433. http://dx.doi.org/10.1143/JPSJ.16.1427

[2] Yamanishi, T. (1962) Hall Effect in the Viscous Flow of Ionized Gas through Straight Channels. 17th Annual Meeting, 
Physical Society of Japan, 5, 29.

[3] Sherman, A. and Sutton, G.W. (1961) Magnetohydrodynamics. Evanston, 173-175.

[4] Katagiri, M. (1969) The Effect of Hall Currents on the Viscous Flow Magnetohydrodynamic Boundary Layer Flow Past a Semi-Infinite Flat Plate. Journal of the Physical Society of Japan, 27, 1051-1059. http://dx.doi.org/10.1143/JPSJ.27.1051

[5] Pop, I. and Watanabe, T. (1994) Hall Effect on Magnetohydrodynamic Free Convection about a Semiinfinite Vertical Flat Plate. International Journal of Engineering Science, 32, 1903-1911. http://dx.doi.org/10.1016/0020-7225(94)90087-6

[6] Aboeldahab, M.E. and Elbarbary, M.E. (2001) Hall Current Effect on Magnetohydrodynamic Free Convection Flow Past a Semi-Infinite Plate with Mass Transfer. International Journal of Engineering Science, 39, 1641-1652. http://dx.doi.org/10.1016/S0020-7225(01)00020-9

[7] Eichhorn, R. (1960) The Effect of Mass Transfer on Free Convection. Journal of Heat Transfer, 82, $260-263$. http://dx.doi.org/10.1115/1.3679928

[8] Vedhanayagam, M., Altenkirch, R.A. and Echhorn, R.A. (1980) A Transformation of the Boundary Layer Equation for Free Convection Flow Past a Vertical Flat Plate with Arbitrary Blowing and Wall Temperature Variation. International Journal of Heat and Mass Transfer, 23, 1236-1288. http://dx.doi.org/10.1016/0017-9310(80)90059-9

[9] Lin, H.T. and Yu, W.S. (1988) Free Convection on Horizontal Plate with Blowing and Suction. Journal of Heat Transfer, 110, 793-796. http://dx.doi.org/10.1115/1.3250564

[10] Hossain, M.A., Alam, K.C.A. and Rees, D.A.S. (1997) MHD Free and Forced Convection Boundary Layer Flow along a Vertical Porous Plate. Applied Mechanics and Engineering, 2, 33-51.

[11] Saha, L.K., Hossain, M.A. and Gorla, R.S.R. (2007) Effect of Hall Current on the MHD Laminar Natural Convection Flow from a Vertical Permeable Flat Plate with Uniform Surface Temperature. International Journal of Thermal Sciences, 46, 790-801. http://dx.doi.org/10.1016/j.ijthermalsci.2006.10.009

[12] Saha, L.K., Siddiqa, S. and Hossain, M.A. (2011) Effect of Hall Current on MHD Natural Convection Flow from Vertical Permeable Flat Plate with Uniform Surface Heat Flux. Applied Mathematics and Mechanics, 32, 1127-1146. http://dx.doi.org/10.1007/s10483-011-1487-9

[13] Bég, O.A., Khan, M.S., Karim, I., Alam, M.M. and Ferdows, M. (2013) Explicit Numerical Study of Unsteady Hydromagnetic Mixed Convective Nanofluid Flow from an Exponentially Stretching Sheet in Porous Media. Applied Nanoscience, 4, 943-957. http://dx.doi.org/10.1007/s13204-013-0275-0

[14] Ferdows, M., Khan, M.S., Alam, M.M. and Sun, S. (2012) MHD Mixed Convective Boundary Layer Flow of a Nanofluid through a Porous Medium Due to an Exponentially Stretching Sheet. Mathematical Problems in Engineering, 2012, Article ID: 408528. http://dx.doi.org/10.1155/2012/408528

[15] Ferdows, M., Khan, M.S., Bég, O.A. and Alam, M.M (2013) Numerical Study of Transient Magnetohydrodynamic Radiative Free Convection Nanofluid Flow from a Stretching Permeable Surface. Journal of Process Mechanical Engineering, 228, 181-196. http://dx.doi.org/10.1177/0954408913493406

[16] Khan, M.S., Karim, I., Islam, M.S. and Wahiduzzaman, M. (2014) MHD Boundary Layer Radiative, Heat Generating and Chemical Reacting Flow Past a Wedge Moving in a Nanofluid. Nano Convergence, 1, 20. http://dx.doi.org/10.1186/s40580-014-0020-8

[17] Khan, M.S., Alam, M.M. and Ferdows, M. (2013) Effects of Magnetic Field on Radiative Flow of a Nanofluid Past a Stretching Sheet. Procedia Engineering, 56, 316-322. http://dx.doi.org/10.1016/j.proeng.2013.03.125

[18] Khan, M.S., Karim, I., Ali, L.E. and Islam, I. (2012) Unsteady MHD Free Convection Boundary-Layer Flow of a Nanofluid along a Stretching Sheet with Thermal Radiation and Viscous Dissipation Effects. International Nano Letters, 2, 24. http://dx.doi.org/10.1186/2228-5326-2-24

[19] Khan, M.S., Karim, I. and Biswas, H.A. (2012) Heat Generation, Thermal Radiation and Chemical Reaction Effects on MHD Mixed Convection Flow over an Unsteady Stretching Permeable Surface. International Journal of Basic and Applied Science, 1, 363-377.

[20] Khan, M.S., Karim, I. and Biswas, H.A. (2012) Non-Newtonian MHD Mixed Convective Power-Law Fluid Flow over a Vertical Stretching Sheet with Thermal Radiation, Heat Generation and Chemical Reaction Effects. Academic Research International, 3, 80-92.

[21] Khan, M.S., Karim, I. and Islam, M.S. (2014) MHD Buoyancy Flows of $\mathrm{Cu}, \mathrm{Al}_{2} \mathrm{O}_{3}$ and $\mathrm{Tio}_{2}$ Nanofluid near Stagnation-Point on a Vertical Plate with Heat Generation. Physical Science International Journal, 4, 754-767. http://dx.doi.org/10.9734/PSIJ/2014/9074

[22] Khan, M.S., Karim, I. and Islam, M.S. (2014) Possessions of Chemical Reaction on MHD Heat and Mass Transfer Nanofluid Flow on a Continuously Moving Surface. American Chemical Science Journal, 4, 401-415. 
http://dx.doi.org/10.9734/ACSJ/2014/5422

[23] Khan, M.S., Wahiduzzaman, M., Karim, I., Islam, M.S. and Alam, M.M. (2014) Heat Generation Effects on Unsteady Mixed Convection Flow from a Vertical Porous Plate with Induced Magnetic Field. Procedia Engineering, 90, 238-244. http://dx.doi.org/10.1016/j.proeng.2014.11.843

[24] Wahiduzzaman, M., Khan, M.S. and Karim, I. (2015) MHD Convective Stagnation Flow of Nanofluid over a Shrinking Surface with Thermal Radiation, Heat Generation and Chemical Reaction. Procedia Engineering, 105, 398-405. http://dx.doi.org/10.1016/j.proeng.2015.05.025

[25] Wahiduzzaman, M., Khan, M.S., Karim, I., Biswas, P. and Uddin, M.S. (2015) MHD Flow of Fluid over a Rotating Inclined Permeable Plate with Variable Reactive Index. Physical Science International Journal, 6, 144-162.

Nomenclature

\begin{tabular}{|c|c|c|c|}
\hline Symbol & Name & Symbol & Name \\
\hline$x, y, z$ & Cartesian coordinates & $P_{r}$ & Prandtl number \\
\hline$f_{w}$ & Transpiration parameter & $S_{c}$ & Schimidt number \\
\hline$u, v, w$ & Velocity components & $M$ & Magnetic parameter \\
\hline$Q$ & Constant heat flux per unit area & $D_{m}$ & Coefficient of mass diffusivity \\
\hline $\boldsymbol{B}$ & Magnetic field intensity & $c_{p}$ & Specific heat at constant pressure \\
\hline $\boldsymbol{B}_{0}$ & Constant magnetic field intensity & $N_{u}$ & Nusselt number \\
\hline$k$ & Thermal conductivity of the medium & $S_{h}$ & Sherwood number \\
\hline$g_{0}$ & Gravitational acceleration & $\left(\tau_{x}, \tau_{z}\right)$ & Skin-friction coefficients \\
\hline$f^{\prime}$ & Non-dimensional primary velocity & $v_{0}$ & Suction velocity \\
\hline$g$ & Non-dimensional secondary velocity & $\mu$ & Coefficient of viscosity \\
\hline$U_{0}$ & Uniform velocity & $\eta$ & Similarity variable \\
\hline$T$ & Temperature of the flow field & $v$ & Coefficient of kinematics viscosity \\
\hline$T_{w}$ & Temperature at the plate & $\theta$ & Dimensionless fluid temperature \\
\hline$T_{\infty}$ & Temperature of the fluid outside the boundary layer & $\varphi$ & Dimensionless fluid concentration \\
\hline C & Species concentration & $\rho$ & Fluid density \\
\hline$C_{w}$ & Concentration at the plate & $\sigma$ & Electrical conductivity \\
\hline$C_{\infty}$ & Concentration outside the boundary layer & $\beta$ & Coefficient of thermal expansion \\
\hline$G_{r}$ & Grashof number & $\beta^{*}$ & Coefficient of concentration expansion \\
\hline$G_{m}$ & Modified Grashof number & & \\
\hline
\end{tabular}

